\title{
Start Out With The Right Foot....and Follow With The Left
}

\author{
Sharon A. Driscoll \\ University of Arkansas
}

\section{Introduction}

Effective teaching involves more preparation than just lecture notes to be written on the board for students to copy. Effective teaching involves two-way interaction between the class and the instructor. The stage is set for this interaction on the first day of class, and so it is important to give thought to how that interaction is to proceed. Will you ask students questions during lecture? Should they bring their books and calculators? Will there be group learning activities? Will active learning be a large part of the class? While minor changes can be made based on the class character, the answers to these questions and more should be made prior to the start of the semester and discussed with the student during the first week of class. In most cases, the answer to all of these questions for chemical engineering students should be YES. Not only are active learning activities important for promoting student learning, recent results of profiling student learning preferences have indicated that the majority of chemical engineering students learn more effectively by working problems themselves. This paper provides suggestions for noncourse material activities for the first week activities, followed by a brief discussion of teaching and learning. One suggestion related to both topics is to profile student learning preferences using VARK catalyst. This inventory will be briefly discussed along with the implications and results obtained from classes in chemical engineering.

\section{First Week of Class}

Take control of the class during the first week, but include some activities that are not directly related to the course material. Before the first class, have the final syllabus prepared. Take time to discuss the syllabus and the different requirements for the course. Talk about your teaching philosophy. If you plan to use group activities, explain how interaction is of benefit to the students. If you want them to use their calculator and book in class, make sure they know to bring it and be sure to have them use it regularly. Talking to the students about how you will organize activities helps prepare the students for how you teach. Below are included specific activities with comments and suggestions for the first week.

(1) Go over the syllabus. The syllabus reflects the organizational characteristics of the class. Unclear rules and requirements can come back to haunt you. Put in grade information (how many points for homework, exam, etc.) and tentative test dates. State your policy on late work and make-up exams. State your policy on office hours and provide contact information such as office number, phone number, and e-mail address. Provide information on topics/chapters covered from the textbook. One common question I get mid-semester around exam time is "what have we covered and what will be on the test." I try to have page numbers listed in the syllabus and refer back to it, adding where we have 
ended. Some professors I know have given an ungraded "quiz" where students find specific information from the syllabus.

(2) Collect names of students in a manner you can use. Either individually, or using suggestion (3) I ask the students fill out an index card with their preferred name, how to pronounce it phonetically if uncommon, e-mail address, and one or more significant facts that will help me remember them. Although few of the "facts" are physically descriptive, they still help me connect the name with the face of the student.

I follow up on this activity in two ways. E-mail is used to communicate quick corrections, clarifications, and changes in schedule or homework. I use the cards the first few weeks of class to call on students and match names with faces. I shuffle the cards once, then when I ask a question in class, I have a random way to call on students and begin learning names and faces.

Other professors use pictures instead of words. Students are asked to write their names on a piece of paper, and during the first week each has a picture taken with a camera. The professor then goes through the pile and memorizes faces and names.

Learn the student's names - in many cases it makes them study more, they are more hesitant to miss class for unimportant reasons, and makes it easier for them to ask and answer questions. My goal is always to learn names by the third week of the sixteenweek semester class. Before using index cards it took much longer to memorize names. Some professors choose to meet with students individually.

(3) Student Interaction. During the semester, I encourage students to work together. I also plan group activities during class where communication becomes important. These activities run smoother when students feel comfortable with each other. However, freshmen students in their first semester and students taking summer classes are usually strangers to each other. To promote interaction in these classes, on the first day I divide students up into pairs or small random groups and have them talk to each other. They are asked to fill out the index cards, with someone else writing down the information name, e-mail, and one or more significant interesting and identifying facts. After some period of time, introductions are made to the whole class.

Student interaction can also be tried in the form of a game by having a list of questions and a small "prize" for the first one to fill out the form. Questions can be things like "find someone whose last name begins with...."

Follow through with this activity by assigning groups and asking students to work on problems together during class. These are not turned in for a grade, but are of benefit to students. Another option is to allow an assigned group to turn in a combined homework assignment. 
(4) Give a "test" to profile student learning styles. Each class will have a different personality in part due to the different learning styles of the students in the class. Everyone prefers to receive information in his or her own way.

There are many different profiling tests available. The test I use is called VARK catalyst. VARK is an acronym for different learning style preferences. V stands for Visual, A for Aural, $\mathrm{R}$ for Read/write, and $\mathrm{K}$ for Kinesthetic (hands-on). One advantage of using VARK is that it is available over the web (www.active-learning-site.com). The test can be printed out and given to the students in class. The test is multiple choice and the instructions for grading the test are fairly simple - and also available at the web site. The results are easy to understand and useful for both students and the instructor. Profiling a class using VARK does not take a lot of time, but should be followed by a brief discussion with the class of learning styles. The students can use their own results to improve study habits based on suggestions available.

Additional information and the results of profiling junior and freshmen level students in chemical engineering will be discussed in more detail later. The information can help an instructor to determine what type of presentation of material is most effective for student learning and retention. In chemical engineering, $\mathrm{K}$ is the dominant preferred learning mode. This led me to increase the number of in-class problem solving activities.

\section{Teaching and Learning}

Often a Ph.D. is considered sufficient training for teaching a class. Some new teachers were lucky enough to have gained experience lecturing as graduate students; others go through graduate student/faculty development programs. While there are many different theories on teaching and learning, most have one thing in common: a belief that the traditional lecture format is not the optimum method for presenting information to the majority of students that we wish to have them retain.

My first experience teaching a technical course brought mixed results. I often started the lecture with a short review of theory, and continued straight into an example. When I would stop to ask a question, I was met with blank faces. Somewhere I had lost the attention of the class. By trial and error, I started including more active learning activities in the classroom to try to liven things up. Initially, I would talk about applications after covering the theory. I reversed this to emphasize the importance of the subject fist. To break things up, about halfway through the theory I would stop with a question about what I had just covered. This worked much better than waiting until the end. I started asking students to bring calculators and feed me numbers during examples. Sometimes the class was started by having students work a simple problem from the previous day's lecture. These things all helped tremendously, but why? I found part of the answer at a teaching workshop given by Dr. R. M. Felder and Dr. R. Brent ${ }^{1}$.

One of the problems related to the traditional lecture is the attention span of students. Research has shown there to be a limited time span for optimal retention of information in lecture format of about 20 minutes. If the presentation continues with no interruption, the amount of 
information retained decreases from a high of $70 \%$ down to $20 \%$ at the end of a 50-minute period. If, however, a break or active exercise is inserted the percentage retained remains near $70 \%$ for the entire period. Breaks in lecture can take many forms. It can be something as simple as a stretch, a thought question with a pause, or a one minute "quiz." Other possibilities include group exercises, small or large group discussions, and demonstrations. What this does is break up the period into small mini-lectures. Each mini-lecture should be complete in itself with an opener, the main body of the lecture, and a brief summary at the end.

Now, with a better understanding of why interrupted lectures work better, I include specific places in my notes for breaks. At least one break will be made for a thought question or demonstration, with another break for interactive examples where I ask for student input, or inclass problem solving by students. In addition to the advantage of breaking up the lecture, I have found that these activities specifically benefit the students in the classroom due to the match with their preferred learning style.

\section{Student Learning Styles}

Some of my early teaching methods were based on personal opinions about how students learn. As happens with most new educators, these opinions were based mainly on how I learn best.

That is a common mistake many instructors make. The feedback I received from the classes was conflicting in that some students liked my teaching style, while others criticized the same methods. This was confusing at the time, but I can now explain the problem - different people learn best through different approaches, and positive feedback resulted when my teaching style matched the student's learning style, while other students with different learning style preferences made the negative comments. It is important to understand how students learn and how teaching styles need to be developed to reach all students.

Each person has his/her own preferred learning style. Many researchers have tried to understand learning styles by developing models based on a combination of research and observation. According to Felder and Silverman ${ }^{2}$, five different "dimensions" categorize learning styles. Preferences for processing of information include spectrums related to: perception (sensing/intuitive), input modality (visual/verbal), organization (induction/deduction), processing (sequential/global), and understanding (active/reflective). If material is presented in the mode preferred by the student, will be more effectively processed by the brain and so better understood. For example, all students can learn from a verbal lecture, and some students prefer this type of input, but other students prefer visual-based input with pictures, diagrams, or demonstrations. Some students want material presented sequentially, while others like to see the information all at once (Global learners). Other students learn better through hands-on experience with problem solving. Understanding this, a professor can mix and match different strategies in order to reach all of the students, in part, in their preferred style.

Fleming and Mills ${ }^{3}$ have developed an alternate model focused on input modality. VARK catalyst is an inventory that divides input modes into four areas: visual (V), aural (A), read/write $(\mathrm{R})$, and kinesthetic (K). Visual mode includes pictures, diagrams, and flowcharts. An aural learner indicates a preference for spoken words, while a read/write learner would prefer them 
written down. Kinesthetic input can include information from other modes, and yet is better defined as experience, simulated, or real, and would include demonstrations, real life examples, and practice situations. While everyone learns through a combination of inputs, a person can have a distinct preference for one type of input, or for a specific combination (multimodal).

I have used VARK to profile learning styles of both freshmen and junior level students in chemical engineering and the results have been interesting ${ }^{4}$. The preferred mode of input for the majority of chemical engineering students (approximately $82 \%$ or $98 / 120$ ) is K, either by itself or in combination with one or more additional modes (multimodal). These students learn most effectively by working problems, hands-on experience, and demonstrations. The least preferred mode was V. Only one student in 120 tested as a purely visual learner. Including the multimodal contributions, 34/120 indicated a preference for visual input. The preference for $\mathrm{A}$ and $\mathrm{R}$ input was found to be approximately equal with $40 \%$ of the students indicating a preference for aural and $43 \%$ for read/write. For more information on the results of the VARK profiles, see Driscoll and Garcia ${ }^{4}$.

Each discipline is likely to have different learning style profiles. The results may be used to shift the emphasis in the direction preferred by the majority of the class, but don't neglect any of the input modes. What learning style research has shown is that the same information may need to be presented in more than one form to reach students in their preferred learning style. To reach more students in their preferred mode, when I sketch a trend or use a graph (V), I take the time to write in words what the trend indicates (R), then step back, pause, and repeat what I have written (A). During class, asking students for input and intermediate numbers in example problems not only keeps them involved in the lecture, but they also benefit through the hands-on interaction $(\mathrm{K})$. Especially when reading a graph is required, during class I have students work through a simple problems in pairs or small group to provided hands-on experience $(\mathrm{K})$. If the subject allows, bring real-life pieces of equipment ( $\mathrm{V}$ and $\mathrm{K}$ ) and discuss real-life problems (A and $\mathrm{K}$ ) and the industrial solution. Small scale hands-on laboratory projects or demonstrations directly related to the theory are now included in the course $(\mathrm{K})$.

\section{Other Suggestions}

Ask for student feedback during the semester. Problems during the semester may not be recalled at the end and is of no use to the students making comments. Try a group problem solving exercise and have them write comments at the end of class. Was it well organized? Was enough time allowed? Were the problems reasonable? Student comments related to these questions can help in planning for the next activity. Make it a short part of the time at the end of class, but anonymous. Ask for the three most important thing learned that day, what the most difficult concept was, or just for comments in general.

Examples of active learning activities have not included such things as making flow charts and concept maps. When tried, these types of activities did not work for me. As this was before I started profiling the classes with VARK, I cannot be sure, but I feel that the lack of "visual" component is a general characteristic of chemical engineers and contributed to the lack of enthusiasm for these visual types of problems. Other instructors have found them to work well. 
When I asked a veteran instructor for advice, he suggested three things. First, start the lecture by telling the students what you are going to teach them. Second, teach them. Third, when your are done tell them what you just taught them. There is nothing wrong with repeating information.

Don't over plan a lecture. My worst experience came from a lecture I spent too much time agonizing about. Students the previous semester had had a difficult time with a particular subject, and so I tried to make sure and cover it well. It ended up even more confusing. The following term, I made light of the "problem area" and they got it, no problem!

Sacrifice content for learning. Focus on the difficult concepts during lecture where you can help the students and make class a learning experience. Some of the suggested activities such as inclass problem solving can take significant amounts of time, but often it is time well spent. Students forget much of what you teach them after the class ends. They can always go back and read the text. Once learned, they are more likely to retain a basic understanding concepts.

Finally, the most import tip I was given when I first started collecting teaching tips - do not try everything at once. Choose what you think would work best for you and the material to be covered. Try one or two new things that you feel will work best for your teaching style.

\section{Summary}

Teaching and learning is a combination of many factors. Understanding your students and the learning process can help you to develop an effective teaching style. Start out on the right foot by preparing for the first lecture with the whole semester in mind. Get to know your students by name and by how they learn. VARK catalyst can also be used to better understand how to effectively interact with the class. Follow through by memorizing student names. Include activities based on teaching and learning - don't try to lecture the whole period. Instead, break up the lecture with activities based on learning style profile results. This will promote student learning and retention on multiple levels. Use a combination of teaching techniques so that more students obtain information in their preferred learning style.

Bibliography

1. Felder, R. M. \& Brent, R.. "Effective Teaching: A Workshop" ASEE Thirty-First Midwest Conference "Those Who Can, Teach..." $31^{\text {st }}$ Midwest Section Conference, ASEE, March 10-11 (1996).

2. Felder, R.M. \& Silverman, L.K. Learning and teaching styles in engineering education. Engineering Education, 78(7), 674-681 (1988).

3. Fleming, N.D. \& Mills, C., Not another inventory, rather a catalyst for reflection. To Improve the Academy, 11(7), 137-155 (1992).

4. Driscoll, S.A., and Garcia, C.E., Preferred Learning Styles for Engineering Students (Session 1430 of this meeting). ASEE national meeting, June 18-21, St. Louis (2000). Submitted for publication in the conference proceedings. 
Biography

SHARON A. DRISCOLL

Sharon Driscoll is an Assistant Professor of Chemical Engineering at the University of Arkansas. She also serves as Faculty Advisor for the Society of Women Engineers. Dr. Driscoll is a registered Professional Engineer in

Arkansas. Dr. Driscoll received a B.S. degree (1984) in Chemical Engineering from the University of Washington in Seattle, and an M.S. (1989) and Ph.D. (1993) from The Ohio State University in Columbus. 